\title{
ASSOCIATED POSTERIOR PELVIC INJURY PATTERNS IN TRANSVERSE-ORIENTED ACETABULAR FRACTURE
}

\section{PADRÕES DE LESÃO PÉLVICA POSTERIOR ASSOCIADA EM FRATURA ACETABULAR COM ORIENTAÇÃO TRANSVERSAL}

\author{
Ozgur Selek ${ }^{1}$, Tuncay Baran ${ }^{2}, U_{\text {mit }} G_{o k}^{3}$, Halil $_{\text {eylan }}{ }^{4}$, Ahmet Yilmaz Sarlak ${ }^{1}$ \\ 1. Kocaeli University School of Medicine, Department of Orthopedics and Traumatology, Umuttepe Kocaeli, Turkey. \\ 2. Erzurum Atatürk State Hospital, Department of Orthopedics and Traumatology, Erzurum, Turkey. \\ 3. Izmit Seka State Hospital, Department of Orthopedics and Traumatology, Izmit, Kocaeli, Turkey. \\ 4. Kocaeli Akademi Hospital, Department of Orthopedics and Traumatology, Izmit, Kocaeli, Turkey.
}

\section{ABSTRACT}

Objective: Our study analyzed the incidence of posterior pelvic injury patterns and their influence on the surgical treatment of transverse-oriented acetabular fractures. Methods: Fifty-one transverse-oriented acetabular fracture cases admitted between 1999 and 2013 were evaluated retrospectively. Comparative studies were performed for groups organized by acetabular fracture type, degree of sacroiliac separation, and postoperative reduction quality. Results: Associated posterior pelvic injuries were found in 34 (66.7\%) of the 51 patients. There were 32 sacroiliac separations in the 34 patients with associated posterior pelvic injury, and ipsilateral sacroiliac separations were more frequent in this subgroup. Measurements guided by computerized tomography showed that 16 sacroiliac separations were $\leq 0.5 \mathrm{~cm}$ (mean $=0.43 \pm 0.14 \mathrm{~cm})$, 10 were $0.5-1 \mathrm{~cm}$ (mean $=0.73 \pm 0.17 \mathrm{~cm})$, and the remaining 6 were $>1 \mathrm{~cm}$ (mean $=1.55 \pm 0.15 \mathrm{~cm}$ ). In the group of 34 patients with associated posterior pelvic injury, acetabular reduction was anatomic in 19 (55.9\%) patients, imperfect in 10 (29.4\%) patients, and poor in 5 (14.7\%) patients. For isolated acetabular fractures, reduction rates were as follows: 12 (70.6\%) anatomic, $3(17.6 \%)$ imperfect, and $2(11.8 \%)$ poor. The rate of anatomic reduction was significantly higher when sacroiliac separation was $\leq 0.5 \mathrm{~cm}(p=0.027)$. Conclusion: Associated posterior pelvic injuries, especially ipsilateral sacroiliac joint separation, accompany most transverse-oriented acetabular fractures and may influence the quality of acetabular reduction. Level of Evidence III, Therapeutic Studies Investigating the Results of Treatment.

Keywords: Acetabulum. Fractures, bone. Pelvic bones. Fracture fixation, internal.

\section{RESUMO}

Objetivo: Nosso estudo analisou a incidência de padrões de lesão pélvica posterior e sua influência no tratamento cirúrgico das fraturas do acetábulo com orientação transversal. Métodos: Cinquenta e um casos de fratura acetabular com orientação transversal foram avaliados retrospectivamente entre 1999 e 2013. Foram realizados estudos comparativos para grupos formados de acordo com o tipo de fratura acetabular, grau de separação sacroiliaca e qualidade da redução no pós-operatório. Resultados: Constataram-se lesões pélvicas posteriores associadas em 34 (66,7\%) dos 51 pacientes. Havia 32 separações sacroiliacas nos 34 pacientes com lesão pélvica posterior associada, e as separações sacroilíacas ipsilaterais foram mais frequentes nesse subgrupo. De acordo com medições guiadas por tomografia computadorizada, 16 separações sacroilíacas foram $\leq 0,5 \mathrm{~cm}$ (média $=0,43 \pm 0,14 \mathrm{~cm}$ ), 10 estavam entre 0,5 e $1 \mathrm{~cm}$ (média $=0,73 \pm 0,17 \mathrm{~cm}$ ) e os 6 restantes foram $>1 \mathrm{~cm}$ (média $=1,55 \pm 0,15 \mathrm{~cm}$ ). No grupo de 34 pacientes com lesão pélvica posterior, a redução acetabular foi anatômica em 19 (55,9\%) pacientes, imperfeita em 10 (29,4\%) pacientes e deficiente em5 $(14,7 \%)$ pacientes. Nas fraturas acetabulares, as taxas de redução foram as seguintes: 12 (70,6\%) anatômicas, $3(17,6 \%)$ imperfeitas e $2(11,8 \%)$ deficientes. A taxa de redução anatômica foi significativamente maior quando o grau de separação sacroilíaca foi $\leq 0,5 \mathrm{~cm}$ ( $p=0,027)$. Conclusão: As lesões pélvicas posteriores associadas, especialmente a separação da articulação sacroiliaca ipsilateral, acompanham a maioria das fraturas do acetábulo com orientação transversal e podem influenciar a qualidade da redução acetabular.

Nivel de Evidência III, Estudos Terapêuticos - Investigação dos Resultados do Tratamento.

Descritores: Acetábulo. Fraturas ósseas. Ossos pélvicos. Fixação interna de fraturas.

Citation: Selek O, Baran T, Gok U, Ceylan HI, Sarlak AY. Associated posterior pelvic injury patterns in transverse-oriented acetabular fracture. Acta Ortop Bras. [online]. 2017;25(4):151-4. Available from URL: http://www.scielo.br/aob.

All authors declare no potential conflict of interest related to this article.

Study conducted in the Department of Orthopedics and Traumatology at Kocaeli University School of Medicine, Umuttepe Izmit Kocaeli, Turkey. Correspondence: Department of Orthopedics and Traumatology, Kocaeli University School of Medicine, 41380 Umuttepe Izmit Kocaeli, Turkey. drozgurselek@gmail.com 


\section{INTRODUCTION}

Judet and Letournel ${ }^{1}$ classified transversely oriented fracture lines running in the sagittal direction involving both the anterior and posterior column of the acetabulum as transverse, transverse-posterior wall, and T-type fractures.

Acetabular fractures are often present with other equally severe associated injuries which could modify the strategy and timing of treatment. ${ }^{2}$ Combined acetabular-pelvic injury has recently gained renewed interest because of the more severe injuries involved and potential involvement of multiple complicating factors, unlike isolated pelvic or acetabular injuries which are less severe..$^{3-5}$

Transversely oriented acetabular fractures were found to be most common in patients with combined pelvic ring disruption and acetabular fracture. ${ }^{3}$ The purpose of this present study was to show that the incidence of associated posterior pelvic injuries in transversely oriented acetabular fractures is higher than reported in the previously literature. We also analyzed the influence of associated posterior pelvic injuries on the surgical treatment of transverse-oriented acetabular fractures.

\section{PATIENTS AND METHODS}

This retrospective study included records of all patients admitted to our hospital with transverse-oriented acetabular fractures between January 1, 1999 and December 31, 2013. All patients signed an informed consent form and the study design and procedures were approved by the institutional review board (KOU KAEK 2013/191). We identified 66 patients, but 15 were excluded for the following reasons: 9 were followed with conservative treatment, 2 were in the pediatric age group, and the computed tomography (CT) images of 4 patients did not include sacroiliac (SI) joints. The remaining 51 patients who had been operated on by the senior author were included in the study; of these, 34 were male (66.7\%). Patient age ranged from 19 to 63 with a mean of 37.6 years. The most common cause of injury was traffic accidents (39 patients) followed by falls from height (10 patients).

A different orthopedic trauma surgeon reviewed and classified preoperative and postoperative plain radiographs and CT images of 51 patients. Transversely oriented acetabular fractures were classified as simple transverse, transverse-posterior wall (PW), and T-type fractures based on the classification by Letournel and Judet. ${ }^{1}$ Disruption of the integrity of the pelvic ring at the posterior as well as acetabulum fracture was defined as associated posterior pelvic injury. ${ }^{6}$ The largest sacroiliac joint displacement was measured in centimeters using axial CT images. ${ }^{6}$ The sacroiliac joint separations were divided into three groups, $\leq 0.5 \mathrm{~cm}, 0.5-1 \mathrm{~cm}$, and $>1 \mathrm{~cm}$, according to the measured displacement. Postoperative acetabular reduction was assessed according to Matta's classification. ${ }^{7,8} \mathrm{~A}$ displacement of $\leq 1 \mathrm{~mm}$ was considered as anatomic, 2-3 mm as imperfect, and $>3 \mathrm{~mm}$ as poor.

Comparative studies were performed for groups, which were formed according to acetabular fracture type, degree of SI separation, and postoperative reduction quality.

\section{Statistical analysis}

Statistical analysis of the data obtained from 51 patients was performed using the chi-square and Fisher's exact tests. A p value of less than 0.05 was considered statistically significant (IBM SPSS Statistics for Windows, Version 20.0. Armonk, NY: IBM Corp., USA).

\section{RESULTS}

Fourteen (27.5\%) out of 51 transversely oriented acetabular fractures were simple transverse, 20 (39.2\%) were transverse-posterior wall, and 17 (33.3\%) were T-type acetabular fractures. (Table 1) Associated posterior pelvic lesions were present in 34 (66.7\%) of the 51 patients; of these, 18 (52.9\%) were ipsilateral, 11 (32.4\%) were contralateral, $3(8.8 \%)$ were bilateral sacroiliac separations, and 2 were sacrum fractures. (Figure 1a-d) Ipsilateral SI separation was higher in pelvic injuries seen in patients with transversely oriented acetabular fractures, but this difference was not statistically significant $(p=0.14)$.

Of 14 patients with simple transverse fractures, 12 (85.7\%) had associated posterior pelvic injury. 12 (60\%) of 20 patients with transverse-PW and 10 (58.8\%) of 17 patients with T-type fractures also had associated posterior pelvic injuries. (Table 1) Comparatively, simple transverse patients had more associated pelvic injuries (mainly ipsilateral SI separation) compared to transverse-PW and T-type patients, but this difference was not statistically significant ( $p=0.209)$.

Overall, $32 \mathrm{SI}$ separations were seen in the 34 patients with associated posterior pelvic injury. Of these, $16 \mathrm{SI}$ separations were $\leq 0.5 \mathrm{~cm}$ (mean $=0.43 \pm 0.14 \mathrm{~cm}), 10$ were $0.5-1 \mathrm{~cm}($ mean $=0.73 \pm 0.17 \mathrm{~cm})$, and the remaining 6 were $>1 \mathrm{~cm}$ (mean $=1.55 \pm 0.15 \mathrm{~cm})$. (Table 2) The mean displacements were $0.66 \pm 0.40 \mathrm{~cm}$ and $0.94 \pm 0.51 \mathrm{~cm}$ in the 18 ipsilateral and 11 contralateral SI separations, respectively. None of the patients with $<0.5 \mathrm{~cm}$ SI separation had internal fixation for SI separation. Of the 16 patients with $>0.5 \mathrm{~cm}$ separation, only 9 were treated using internal fixation for SI separation. Of these 9 patients, 3 had $0.5-1 \mathrm{~cm}$ separation while 6 had $>1 \mathrm{~cm}$ SI separation. (Table 3) In the remaining 23 patients out of the 32 patients with SI separation, this separation was missed preoperatively.

Acetabular reduction was anatomic in 19 (55.9\%) patients, imperfect in $10(29.4 \%)$ patients, and poor in 5 (14.7\%) patients among the 34 patients with associated posterior pelvic injury. The reduction rates in isolated acetabular fractures revealed 12 (70.6\%) anatomic, 3 (17.6\%) imperfect, and 2 (11.8\%) poor reductions. (Figure 2) Nevertheless, no statistically significant difference was found $(p=0.416)$.

Table 1. Pelvic injuries associated with transverse-oriented acetabular
fractures.
\begin{tabular}{c|c|c|c} 
& $\begin{array}{c}\text { Simple } \\
\text { transverse (n:14) }\end{array}$ & $\begin{array}{c}\text { Transverse-posterior } \\
\text { wall (n:20) }\end{array}$ & $\begin{array}{c}\text { T-Type } \\
\text { (n: } 17)\end{array}$ \\
\hline Associated pelvic injury (n:34) & 12 & 12 & 10 \\
\hline Ipsilateral SI Sep. (n:18) & 6 & 7 & 5 \\
\hline Contralateral SI Sep. (n:11) & 4 & 4 & 3 \\
\hline Bilateral SI Sep. (n:3) & 2 & 1 & 0 \\
\hline Sacrum fr. (n:2) & 0 & 0 & 2 \\
\hline
\end{tabular}

SI Sep: sacroiliac joint separation; fr: fracture.
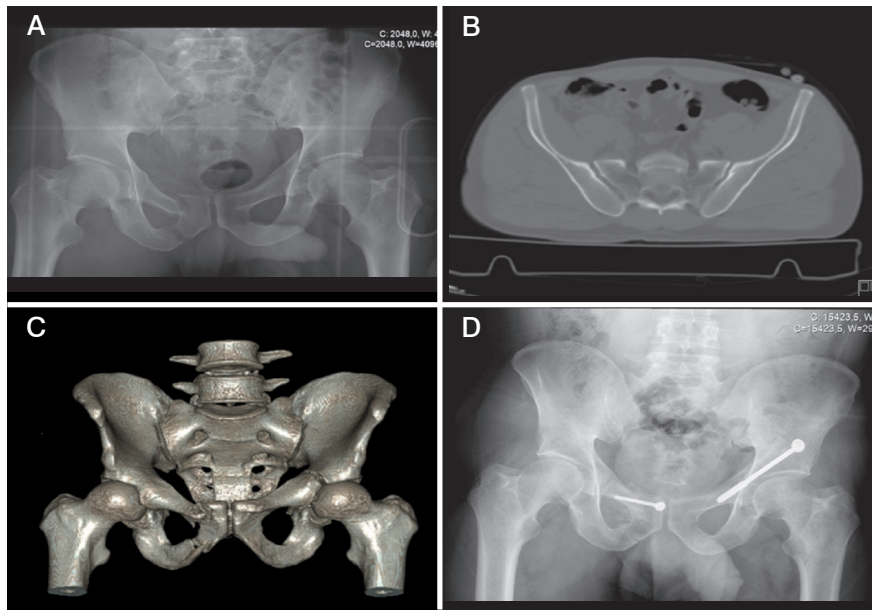

Figure 1. Patient with both transverse acetabular fracture and contralateral sacroiliac joint separation. (A) Preoperative X-ray (B) Preoperative CT scan (C) Preoperative CT scan (3D) (D) Postoperative X-ray. 
The difference between ipsilateral or contralateral SI separation according to fracture reduction rate was insignificant $(p=0.934)$. Additionally, fracture reduction rates did not differ in patients who were treated or not treated with internal fixation for SI separation $(p=0.49)$ There were no cases of poor reduction among the patients with SI separations $\leq 0.5 \mathrm{~cm}$. Four (40\%) patients with SI separation $0.5-1 \mathrm{~cm}$ and 1 (16.7\%) patient with SI separation $>1 \mathrm{~cm}$ had poor reduction. (Table 4$)$ The anatomic reduction rate was significantly higher when the degree of SI separation was $\leq 0.5 \mathrm{~cm}(p=0.027)$.

Table 2. Degree of sacroiliac separation.

\begin{tabular}{c|c|c|c}
\hline & $\begin{array}{c}\text { Simple } \\
\text { transverse (n:14) }\end{array}$ & $\begin{array}{c}\text { Transverse-posterior } \\
\text { wall (n:20) }\end{array}$ & T-Type (n: 17) \\
\hline SI sep. $\leq 0.5 \mathrm{~cm}(\mathrm{n}: 16)$ & 6 & 5 & 5 \\
\hline SI sep. 0.5-1 cm (n:10) & 4 & 4 & 2 \\
\hline SI sep. $>1 \mathrm{~cm}(\mathrm{n}: 6)$ & 2 & 3 & 1 \\
\hline SI sep. Total $(\mathrm{n}: 32)$ & 12 & 12 & 8 \\
\hline
\end{tabular}

Table 3. Sacroiliac separation treatment modality.

\begin{tabular}{c|c|c}
\hline & SI fixate & SI not fixate \\
\hline SI sep. $\leq 0.5 \mathrm{~cm}(\mathrm{n}: 16)$ & 0 & 16 \\
\hline SI sep. $0.5-1 \mathrm{~cm}(\mathrm{n}: 10)$ & 3 & 7 \\
\hline SI sep. $>1 \mathrm{~cm}(\mathrm{n}: 6)$ & 6 & 0 \\
\hline SI sep. Total $(\mathrm{n}: 32)$ & 9 & 23 \\
\hline
\end{tabular}

SI Sep: sacroiliac joint separation.

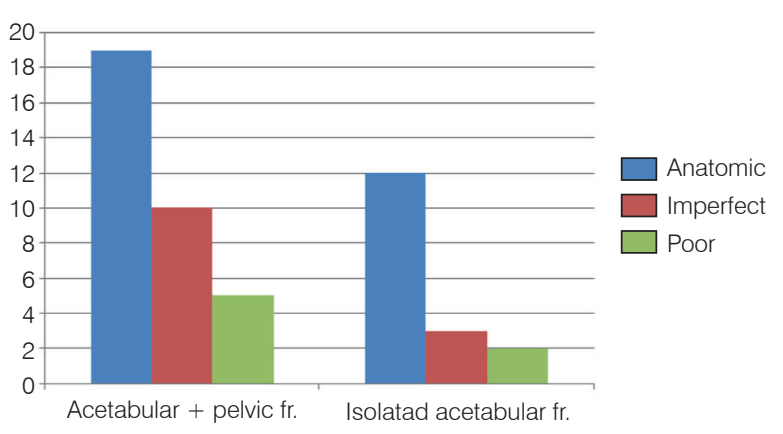

Figure 2. Acetabular reduction rates

Table 4. Acetabular reduction rates by group.

\begin{tabular}{c|c|c|c}
\hline & Anatomic (n/\%) & Imperfect (n/\%) & Poor (n/\%) \\
\hline Degree of Sl sep. & & & \\
\hline$\leq 0.5 \mathrm{~cm}(\mathrm{n}=16)$ & $11(68.7)$ & $5(31.3)$ & $0(0)$ \\
\hline $0.5-1 \mathrm{~cm}(\mathrm{n}=10)$ & $5(50)$ & $1(10)$ & $4(40)$ \\
\hline$>1 \mathrm{~cm}(\mathrm{n}=6)$ & $2(33.3)$ & $3(50)$ & $1(16.7)$ \\
\hline
\end{tabular}

SI Sep: sacroiliac joint separation.

\section{DISCUSSION}

Young and Burgess ${ }^{9,10}$ reflected anecdotally that most combined pelvic and acetabular fractures result from a lateral compression mechanism of injury. Transverse fractures are assumed to result from lateral compression force transmitted via the trochanter or proximal femur or axially along the femur if the hip is in a flexed position at the time of impact. ${ }^{11}$ With the more recent use of superior image resolution and decreased slide thickness, previously unrecognized instability patterns for various pelvic injuries have been analyzed. ${ }^{12}$ It became evident that lateral compression does not completely describe the wide range of injury patterns. ${ }^{13}$ In two recent studies, Osgood and Suzuki analyzed the injury mechanism in combined pelvic-acetabular injury. ${ }^{3,4}$ Osgood analyzed 40 cases and identified anteroposterior compression (APC) or lateral compression (LC) injury mechanisms. ${ }^{4}$ According to Suzuki et al., ${ }^{3}$ 62 posterior pelvic lesions were associated with transverse-type acetabular fractures, and the majority had ipsilateral SI disruption. Unlike previous studies, both of these studies suggested that APC is just as common as LC as the mechanism of injury. Our study supports recent studies indicating complex translational and rotational displacements in patients with combined transverse-oriented fracture and posterior pelvic injury. . $^{3,4}$

Letournel and Judet ${ }^{1}$ reported a $16.1 \%$ incidence of associated pelvic-acetabular injury. Though it was not addressed specifically in the studies by Osgood et al. ${ }^{4}$ and Porter et al., ${ }^{5}$ their studies indicated the incidence of pelvic injury in transverse-oriented acetabular fractures as $59 \%$ and $20.8 \%$, respectively. Our study reveals a higher incidence $(66.7 \%)$ of posterior pelvic injury in transverse-oriented acetabular fractures. Twelve of 14 (85.7\%) simple transverse fracture patients in our study had pelvic injury, which is a higher percentage than that reported by Osgood and Porter. Twelve out of 14 patients with simple transverse fractures in our study had posterior pelvic disruption, mostly in the form of ipsilateral SI disruption, in accordance with Suzuki's findings.

Previous studies have reported that combined posterior pelvic injuries affect acetabular reduction. ${ }^{3,4}$ Excellent outcomes were achieved in cases with associated SI separation of $<0.5 \mathrm{~cm}$, and satisfactory-anatomic reduction was readily obtained. Residual displacement of $<1 \mathrm{~cm}$ in a posterior pelvic lesion has been reported as acceptable, although no previous studies have analyzed the acceptability criteria for posterior pelvic displacement in combined pelvic injury-acetabulum fracture. ${ }^{14,15}$ We found that combined transverse-oriented acetabulum fracture with residual SI separation of $>0.5 \mathrm{~cm}$ is likely to result in unsatisfactory reduction of the acetabular fracture.

Previous research has suggested that reduction can generally be obtained in transverse acetabular fractures by mobilizing the inferior ischiopubic segment. ${ }^{16}$ The literature underestimates the value of mobilizing the superior iliac segment in reducing transverse fracture. We believe it may be essential in transverse acetabular fractures with ipsilateral SI separation to internally rotate the fractured iliac segment while reducing both the SI separation and transverse acetabular fracture.

While the greater energy associated with these injuries, patient condition, and surgical timing may also influence outcome, our study supports the decrease in reduction quality with greater SI separation. All patients with transverse-oriented fractures should be thoroughly evaluated to rule out accompanying posterior injuries that may possibly influence outcomes.

The value of this study may be limited by its retrospective design, the lack of a control group, and the relatively small number of patients. We also did not investigate other important factors that may influence the quality of fracture reduction, such as bone quality and preoperative fracture displacement. It may be difficult to blame a single mechanism of injury in the case of combined acetabulum fracture-posterior pelvic injury. For posterior SI separations, the most common associated injury pattern, more than $0.5 \mathrm{~cm}$ may be critical, since this could affect acetabular reduction. A much larger sample with greater power may be needed to ascertain the true differences in the incidence of injury mechanisms as well as other factors influencing acetabular reduction in this heterogeneous group. 
AUTHORS' CONTRIBUTIONS: Each author made significant individual contributions to this manuscript. OS (0000-0003-0149-2492)* and AYS were the main contributors in drafting the manuscript. TB (0000-0002-7052-4171)*, UG (0000-0003-2659-7952) ${ }^{\star}$, and HC (In memoriam) performed surgery, followed patients, and gathered clinical data. OS and TB evaluated the data for the statistical analysis. OS, UG, HC, and AYS (0000-0003-2659-7952) * performed the literature search, reviewed the manuscript, and contributed to the intellectual concept of the study. ${ }^{\star}$ ORCID (Open Researcher and Contributor ID).

\section{REFERENCES}

1. Letournel E, Judet R. Fractures of the acetabulum. 2nd ed. New York: Springer-Verlag; 1993.

2. Petsatodis G, Antonarakos P, Chalidis B, Papadopoulos P, Christoforidis J, Pournaras J. Surgically treated acetabular fractures via a single posterior approach with a follow-up of 2-10 years. Injury. 2007;38(3):334-43.

3. Suzuki T, Smith WR, Hak DJ, Stahel PF, Baron AJ, Gillani SA, Morgan SJ. Combined injuries of the pelvis and acetabulum: nature of a devastating dyad. J Orthop Trauma. 2010;24(5):303-8

4. Osgood GM, Manson TT, O'Toole RV, Turen $\mathrm{CH}$. Combined pelvic ring disruption and acetabular fracture: associated injury patterns in 40 patients. J Orthop Trauma. 2013;27(5):243-7.

5. Porter SE, Schroeder AC, Dzugan SS, Graves ML, Zhang L, Russell GV. Acetabular fracture patterns and their associated injuries. J Orthop Trauma. 2008;22(3):165-70.

6. Scheyerer MJ, Osterhoff G, Wehrle S, Wanner GA, Simmen HP, Werner CM. Detection of posterior pelvic injuries in fractures of the pubic rami. Injury. 2012;43(8):1326-9.

7. Matta JM, Mehne DK, Roffi R. Fractures of the acetabulum. Early results of a prospective study. Clin Orthop Relat Res. 1986;(205):241-50.

8. Matta JM. Fractures of the acetabulum: accuracy of reduction and clinical results in patients managed operatively within three weeks after the injury. $J$ Bone Joint Surg Am. 1996;78(11):1632-45.
9. Young JW, Burgess AR, Brumback RJ, Poka A. Pelvic fractures: value of plain radiography in early assessment and management. Radiology. 1986;160(2):445-51.

10. Young JW, Burgess AR, Brumback RJ, Poka A. Lateral compression fractures of the pelvis: the importance of plain radiographs in the diagnosis and surgical management. Skeletal Radiol. 1986;15(2):103-9.

11. Judet R, Judet J, Letournel E. Fractures of the acetabulum: classification And surgical approaches for open reduction. Preliminary report. J Bone Joint Surg Am. 1964;46:1615-46.

12. Sagi HC, Coniglione FM, Stanford JH. Examination under anesthetic for occult pelvic ring instability. J Orthop Trauma. 2011;25(9):529-36.

13. Lefaivre KA, Blachut PA, Starr AJ, Slobogean GP, O'Brien PJ. Radiographic displacement in pelvic ring disruption: reliability of 3 previously described measurement techniques. J Orthop Trauma. 2014;28(3):160-6

14. Henderson RC. The long-term results of nonoperatively treated major pelvic disruptions. J Orthop Trauma. 1989;3(1):41-7.

15. McLaren AC, Rorabeck $\mathrm{CH}$, Halpenny J. Long-term pain and disability in relation to residual deformity after displaced pelvic ring fractures. Can J Surg. 1990;33(6):492-4.

16. Smith WR, Ziran BH, Morgan SJ. Fractures of the pelvis and acetabulum. New York: Informa Healtcare; 2007. 